\title{
Value transfer contributes to ambiguous-cue discrimination learning
}

\author{
Peter J. Urcuioli and Sarah Michalek \\ Purdue University, West Lafayette, Indiana
}

\begin{abstract}
Pigeons learned two concurrent simultaneous discriminations in which the $\mathrm{S}-$ for one served as the $\mathrm{S}+$ for the other. When all correct choices were reinforced, accuracy on the former (positive vs. ambiguous-cue or PA) discrimination was lower than on the latter (negative vs. ambiguous-cue or NA) discrimination. When correct choices on the PA discrimination were intermittently reinforced, however, pigeons chose the $\mathrm{S}-$ more often than the $\mathrm{S}+$ on those trials. By contrast, intermittently reinforcing correct choices on the NA discrimination did not affect NA-trial accuracy but yielded higher PA-trial accuracy relative to continuous reinforcement. Together with a separate preference assessment, these results indicate that value transfer, in which some of the positive value accrued by an $\mathrm{S}+$ transfers to its companion $\mathrm{S}-$, contributes to ambiguous-cue performances.
\end{abstract}

Ambiguous cue tasks consist of two simultaneous discriminations in which the $\mathrm{S}-$ in one discrimination serves as the $\mathrm{S}+$ in the other (Thompson, 1954). This stimulus is called the ambiguous cue (A) because its status as a signal for reinforcement or nonreinforcement depends upon the other stimulus with which it appears. The A cue is an Swhen it appears with a reinforced or positive $(\mathrm{P})$ stimulus. Conversely, the A cue is an $\mathrm{S}+$ when it appears with a nonreinforced or negative $(\mathrm{N})$ stimulus. Thus, the two discriminations or trial types in this task are designated PA and NA.

Typically, discriminative performance on PA trials is less accurate than on NA trials, a finding known as the ambiguous-cue or PAN effect. It has been observed in pigeons, monkeys, children, and adults with mental retardation (e.g., Fletcher, Grogg, \& Garske, 1968; Hall, 1980; Richards \& Marcattilio, 1975). The standard explanation for the effect, the interfering cue hypothesis (Fletcher \& Garske, 1972; Zeaman \& House, 1962; see also Berch, 1974; Boyer \& Polidora, 1972), states that the A cue interferes with correct selection of the P stimulus on PA trials because subjects must choose between two excitatory stimuli: the always reinforced $\mathrm{P}$ stimulus and the partially reinforced A stimulus. By contrast, no such interference is present on NA trials because the choice here is between a partially reinforced and a nonreinforced stimulus.

The interfering cue hypothesis readily explains most of the reported findings in this literature. Nonetheless, recent analyses of discrimination learning suggest that other associative factors may also contribute to performance. Specifically, Zentall and his associates (Zentall \& Clement, 2001; Zentall \& Sherburne, 1994) and von Fersen et al. (1991) have proposed that the $S$ - in a simultaneous discrimination acquires some positive or excitatory value from the $\mathrm{S}+$ which it accompanies. Stated otherwise, some of the value that directly accrues to an $\mathrm{S}+$ via reinforced responding to it transfers to the $\mathrm{S}-$ with which it is presented. According to this hypothesis, the total value of a stimulus in a simultaneous discrimination equals its direct value plus any "indirect" value it receives via positive value transfer. Given that ambiguous-cue tasks are comprised of simultaneous discriminations, one would suspect that value transfer operates here as well.

We devised a test of this idea by constructing an ambiguous-cue task in which the interfering cue and value transfer hypotheses make different predictions. That test involved scheduling partial reinforcement on PA trials. The interfering cue hypothesis, which considers only the direct values of the discriminative stimuli (i.e., the values those stimuli accrue via direct reinforced or nonreinforced responding to them), predicts that if correct choice of the P stimulus on PA trials is reinforced only $50 \%$ of the time, subjects should be indifferent to the $\mathrm{P}$ and $\mathrm{A}$ stimuli. In other words, since the overall probability of reinforcement for both stimuli under these conditions is 0.5 , PA-trial accuracy should be about $50 \%$.

By contrast, the value transfer hypothesis makes the interesting prediction that partial reinforcement of the PA discrimination will yield below chance accuracies: Subjects should select the $S$ - on PA trials (the A cue) more often than the $\mathrm{S}+$ (the P cue). This should occur despite equal direct values for $\mathrm{P}$ and $\mathrm{A}$ because the A cue will also get indirect positive value from the intermittently reinforced $(\mathrm{P})$ stimulus with which it appears, whereas $\mathrm{P}$ cannot get any indirect positive value from $\mathrm{A}$ (because $\mathrm{A}$ is never reinforced when it appears with P). Consequently, the overall value of A (the $\mathrm{S}-$ ) will exceed the overall value of $\mathrm{P}($ the $\mathrm{S}+$ ). 


\section{EXPERIMENT 1}

This study examined whether partial reinforcement for correct choice on the PA trials of an ambiguous-cue task would produce accuracy levels below chance, as predicted by value transfer. To assess the effects of partial reinforcement per se, a separate group was run in which correct NAtrial choices were partially reinforced. A standard, continuously reinforced group served as a baseline condition.

\section{Method}

\section{Subjects}

Twelve adult White Carneaux pigeons from the Palmetto Pigeon Plant (Sumter, SC) served. Nine were experimentally naive; three had previously participated in a two-alternative delayed matching experiment. All were housed individually in stainless-steel cages in a colony room on a 14:10-h day:night cycle with lights on at 07:00. They were maintained at $80 \%$ of their free-feeding body weights during the experiment. On days on which pigeons were not run, they received 12-18 g of food in their home cages. Grit and water were freely available.

\section{Apparatus}

The experiment was run in two identically configured BRS/LVE (Laurel, MD) chambers (Model PIP-016 panels inside Model SEC002 enclosures). The interior dimensions of the chamber and the panel layout are described in detail elsewhere (e.g., Urcuioli, Vu, \& Proctor, 2005). Briefly, three 2.5 -cm-diameter clear plastic pecking keys were equally spaced about $25 \mathrm{~cm}$ above the floor of the chamber. Behind each was a 12-stimulus inline projector (Model IC-901 -IDD) that could display a small, solid inverted white triangle on the center key, and red, green, blue, yellow and white homogeneous fields on the left and right keys (BRS/LVE Pattern No. 692). General illumination was provided by a partially covered General Electric 1829 bulb located $5.7 \mathrm{~cm}$ above the center key and whose light was directed toward the ceiling. Food (Purina Pigeon ProGrains) was delivered via a feeder mounted behind the panel and accessible through a $5.8 \times 5.0-\mathrm{cm}$ opening $13 \mathrm{~cm}$ below the center key. Continuously running blower fans provided ventilation and masking noise. All experimental events were controlled by IBM-compatible 386 computers.

\section{Procedure}

Prior to the start of the experiment, pigeons were randomly divided into three groups with the restriction that each group contain one experienced bird. Two pigeons from each group were run in each experimental apparatus.

Preliminary training. Experimentally naive birds were initially trained to eat quickly and reliably from a raised and lit feeder, followed by shaping of the keypeck response to the center-key triangle. All birds then received three 60-trial sessions during which single pecks to the stimuli they would later encounter in the ambiguous-cue task (i.e., triangle on the center key, and red, green, and white on the left and right side keys) were reinforced. Trials were separated by a 10 -sec intertrial interval (ITI). The houselight remained on continuously.

Ambiguous-cue discrimination learning. Next, all pigeons were trained on an ambiguous-cue discrimination in which white was the ambiguous (A) cue. Red and green served as the positive $(\mathrm{P})$ and negative $(\mathrm{N})$ stimuli, counterbalanced across the four pigeons in each group. Each of the 60 trials in a session began with the small white triangle on the center key. A single peck to this "trial-ready" stimulus turned it off and immediately produced two discriminative stimuli on the side keys. A single peck to either discriminative stimulus then turned both off and produced either food reinforcement or a dark time-out period of equal duration. The next trial then began following a 10-sec ITI, the first $9 \mathrm{sec}$ of which was dark. The houselight was turned on for the last $1 \mathrm{sec}$ of the ITI and the remained on until the end of the next reinforcement or an incorrect choice.
The $\mathrm{P}$ and A stimuli appeared together on half of the trials in each session, and the $\mathrm{N}$ and $\mathrm{A}$ stimuli appeared together on the remaining trials. On PA trials, a single peck to the P stimulus was reinforced in a manner that depended on group assignment, whereas a single peck to the white (A) stimulus was nonreinforced. On NA trials, a single peck to the white (A) stimulus was reinforced in a manner that also depended on group assignment, whereas a single peck to the $\mathrm{N}$ stimulus was nonreinforced. Trial types occurred in random order, with each discriminative stimulus appearing equally often on the left and right keys.

For pigeons in Group Continuous, every correct choice on both trial types was reinforced. For pigeons in Group PA-Partial, correct PA-trial choices produced food with a probability of 0.5 , whereas all correct NA-trial choices were reinforced. For pigeons in Group NAPartial, correct NA-trial choices produced food with a probability of 0.5 , whereas all correct PA-trial choices were reinforced. The duration of food reinforcement was constant within a session, but varied from 2 to $6 \mathrm{sec}$ across birds and across sessions in order to maintain body weights as close to their $80 \%$ values as possible.

Type I error rate for all statistical analyses was set at .05 on a perdecision basis using the tabled values provided by Rodger (1975).

\section{Results and Discussion}

Figure 1 shows mean accuracy on PA trials (filled symbols) and NA trials (open symbols) for each group over 30 training sessions. Different symbols plot data from the different groups.

All three groups showed an ambiguous-cue (or PAN) effect: PA-trial performances were less accurate than NA-trial performances, as seen by the separations between the corresponding filled and open symbols. More important, the size of the effect varied across groups. The largest was observed in Group PA-Partial (triangles), the smallest in Group NA-Partial (circles), and an intermediate-sized effect in Group Continuous (squares). This variation was almost entirely attributable to performances on the PA trials, given that the level of NA-trial accuracy was comparable across groups throughout most of training. Analysis of variance with group, trial type and blocks of sessions as factors showed an overall effect of group $[F(2,9)=64.56]$, trial type $[F(1,9)=364.06]$, and group $\times$ trial type interaction $[F(2,9)=70.00]$. All interactions with blocks as a factor were also significant [group $\times$ block, $F(28,126)=1.89$; trial type $\times$ block, $F(14,126)=8.76$; group $\times$ trial type $\times$ block, $F(28,126)=1.69]$.

Follow-up analyses over the last five blocks of sessions when performances appeared to have stabilized showed no significant between-groups difference on NA trials $[F(2,9)=2.62]$ but a significant between-groups difference on PA trials $[F(2,9)=112$. 86]. For Group Continuous, accuracy on the PA trials was not significantly above chance $(50 \%)$ levels $[t(3)=1.85]$. By contrast, for Group PA-Partial, accuracy on the PA trials was significantly below chance $[t(3)=-8.46, p<.05]$, whereas for Group NA-Partial, it was significantly above chance $[t(3)=9.94, p<.05]$.

The PA - NA accuracy difference observed in each group replicates the basic ambiguous-cue effect (e.g., Fletcher et al., 1968). The more important finding, however, was that PA-trial accuracy was significantly below $50 \%$ in Group PA-Partial: When confronted with a choice 


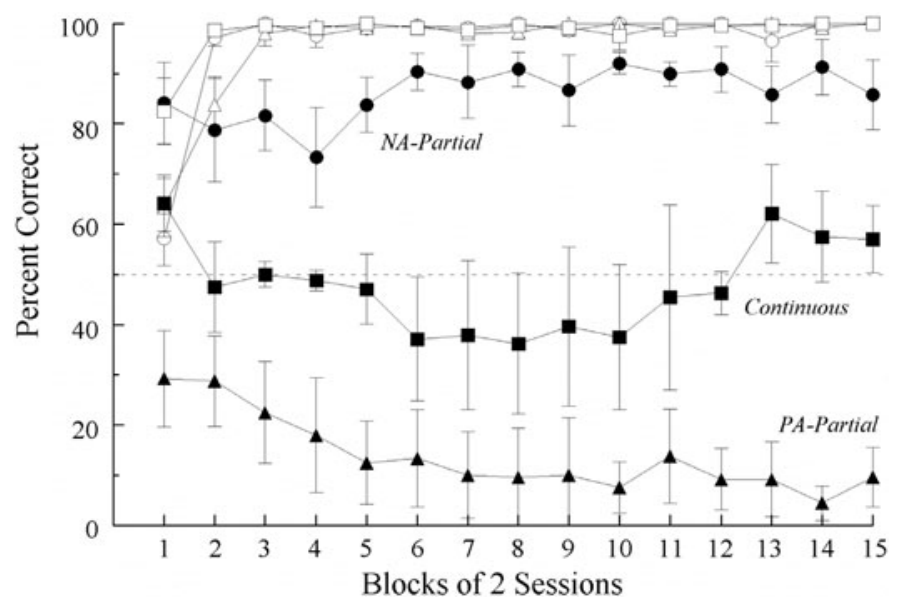

Figure 1. Percentage of correct choices $( \pm 1 S E M)$ on PA and NA trials during each group's acquisition of the ambiguous-cue discrimination in Experiment 1. Different groups are represented by different symbols that plot both PA-trial accuracy (filled symbols) and NA-trial accuracy (open symbols).

between a partially reinforced $\mathrm{S}+(\mathrm{P}$ stimulus $)$ and a nonreinforced $\mathrm{S}-$ (A stimulus), these birds preferred the latter. Indeed, in a number of sessions, some of the Group PA-Partial birds always chose the $\mathrm{S}-$ (i.e., their PA-trial accuracy was $0 \%$ ). This odd finding is not explicable in terms of the probability of reinforcement for pecking the $\mathrm{P}$ stimulus $(50 \%)$ versus the overall probability of reinforcement for pecking the A stimulus (50\%), for obvious reasons. The finding makes sense, however, on the assumption that the net value of the A stimulus was actually higher than the net value of the $\mathrm{P}$ stimulus.

Note, too, that the behavior exhibited by the Group PAPartial birds did not simply reflect the effects of partial reinforcement per se. After all, partially reinforcement of correct NA-trial choices in Group NA-Partial enhanced, rather than diminished, pigeons' accuracy on the PA trials while leaving NA-trial accuracy unaffected. Both the interfering cue hypothesis and value transfer theory predict these latter results.

\section{EXPERIMENT 2}

Experiment 2 was designed to provide independent and corroborating evidence for value transfer in ambiguous-cue tasks. One method to assess value transfer is to test a subject's preference between two $\mathrm{S}-$ stimuli, one that accompanied an always reinforced $\mathrm{S}+$ in training and another that accompanied a partially reinforced $\mathrm{S}+$ in training. Because each $\mathrm{S}-$ has zero direct value (responding to these stimuli is never reinforced), the logic of this test is that a preference reflects their different indirect values (Steirn, Weaver, \& Zentall, 1995; Zentall \& Sherburne, 1994; although see Aitken, 1999). Thus, an $S-$ appearing with an always reinforced $\mathrm{S}+$ should be preferred to an $\mathrm{S}-$ appearing with a partially reinforced $\mathrm{S}+$ because the always reinforced $\mathrm{S}+$ will have a larger direct value and, hence, more value to transfer to its accompanying $\mathrm{S}-$.
In Experiment 2, then, pigeons were given a choice between the $\mathrm{S}$ - from the NA trials of an ambiguous-cue discrimination and the $\mathrm{S}-$ stimulus from a separate, concurrently trained discrimination $(\mathrm{X}+\mathrm{Y}-)$ in which correct choice of the $\mathrm{S}+$ was always reinforced. Value transfer predicts that pigeons should select the $S-$ from the NA trials $(\mathrm{N})$ less often than the alternative $\mathrm{S}-(\mathrm{Y})$ from the separate, XY discrimination. In other words, pigeons should show a preference for Y.

\section{Subjects and Apparatus}

\section{Method}

Fourteen White Carneaux pigeons, all with previous experience in various delayed matching tasks and two with previous experience in a Simon discrimination task (Urcuioli et al., 2005, Experiment 4) were run. Six pigeons (including the two with experience in the Simon task) represented one group from a larger study in which the other groups were not relevant to the present issues. The remaining 8 pigeons were run separately for the sole purpose of the present experiment. All were housed and maintained in the same fashion as in Experiment 1, and all were familiar with most, if not all, of the stimuli used here in the locations at which they would appear. The same apparatus was used.

\section{Procedure}

Preliminary training, minus initial food hopper and keypeck shaping (which were unnecessary), was identical to that of Experiment 1.

All pigeons were then trained for either 48 (set of 6 pigeons) or 25 (set of 8 pigeons) sessions on an ambiguous-cue discrimination and on a separate two-choice (XY) discrimination. Each 90-trial training session was divided equally among PA, NA, and XY trials with white as the ambiguous (A) cue.

For the 6 birds that were part of another study, half had red as the reinforced $(\mathrm{P})$ stimulus on PA trials and green as the nonreinforced (N) stimulus on NA trials, whereas the other half had the opposite stimulus assignments. For all of these birds, blue was the reinforced (X) stimulus and yellow was the nonreinforced (Y) stimulus on the $\mathrm{XY}$ trials. For the other 8 birds, half had yellow as the reinforced (P) stimulus and red as the nonreinforced $(\mathrm{N})$ stimulus, whereas the other half had the opposite stimulus assignments. Blue and green were counterbalanced as the $\mathrm{X}$ and $\mathrm{Y}$ stimuli for these latter birds. All other details were identical to training in Experiment 1. 
Ten test sessions then followed. Each contained 90 training trials plus 10 randomly intermixed trials involving a choice between the $\mathrm{N}$ stimulus (the $\mathrm{S}-$ on the NA trials) and the $\mathrm{Y}$ stimulus (the $\mathrm{S}-$ on the $X Y$ trials). On the test trials, food was presented with a probability $=0.5$ no matter which stimulus ( $\mathrm{N}$ or $\mathrm{Y}$ ) was pecked.

\section{Results and Discussion}

The data from all pigeons were combined because there were no significant differences in overall baseline performances between the two sets of birds $[F(1,12)=.50]$ or in the interaction between sets and trial types $[F(2,24)=$ .58]. Throughout training, PA-trial accuracy was considerably lower than NA-trial accuracy, a difference that held over the 10 test sessions: $70.9 \%$ versus $97.0 \%$ correct, respectively $[F(1,13)=56.82]$. Accuracy on the XY trials during training was virtually identical to accuracy on the NA trials, and again during testing: $97.1 \%$ versus $96.9 \%$ correct, respectively $[F(1,13)=.04]$.

When given a choice between the two $\mathrm{S}-$ stimuli $(\mathrm{N}$ and $\mathrm{Y})$, pigeons chose the $\mathrm{Y}$ stimulus $64.6 \%$ of the time on average across the 10 test sessions, a preference that differs significantly from chance $(50 \%)[t(13)=2.58, p<.05]$. The size of this effect was diminished somewhat by three birds with exceptionally strong position preferences throughout testing (i.e., pecking either the left or right key on $95 \%$ or more of the 100 test trials). If their data are excluded on the grounds that their stimulus preferences could not be adequately assessed, the average $\mathrm{Y}$ preference for the remaining 11 birds was $69.1 \%$ [ $t(10)=2.91, p<.05]$. The data for these 11 birds are shown in Figure 2. Individually, 7 of them showed a significant preference for $Y$ [all $\chi^{2}(1)>4.80$ ].

These preference results complement those of Experiment 1 by providing a different assessment of value transfer in ambiguous-cue discrimination learning. In the absence of value transfer, pigeons should be indifferent between the $\mathrm{N}$ stimulus from the NA trials of the ambiguous-cue task and the $\mathrm{Y}$ stimulus from the concurrently trained $\mathrm{XY}$ discrimination. They were not. Although this sort of result might arise from more nonreinforced choices of the $\mathrm{N}$ than the $\mathrm{Y}$ stimulus during training (thus yielding greater avoidance of $\mathrm{N}$ in testing), the correlation between the percentage of nonreinforced $\mathrm{N}$ choices (vis-à-vis $\mathrm{Y}$ choices) in training and preference for $\mathrm{Y}$ in testing was negative $(r=$ $-0.41)$ rather than positive. Furthermore, on an absolute basis, there were very few nonreinforced choices throughout training. For instance, the average numbers of incorrect choices of $\mathrm{N}$ and of $\mathrm{Y}$ over all 1,440 NA and 1,440 XY trials were 26.6 and 10.7, respectively, for the birds trained for 48 sessions, and these were mostly confined to the first two or three sessions. For the other 8 birds, the average of numbers of $\mathrm{N}$ and $\mathrm{Y}$ choices over all $750 \mathrm{NA}$ and $750 \mathrm{XY}$ trials were 23.6 and 16.8 , respectively, again mostly confined to the initial training sessions.

\section{GENERAL DISCUSSION}

The present findings confirm straightforward predictions from the value transfer hypothesis. Their uniqueness lies in the fact that the value transfer should, and does, produce the unusual finding that subjects actually respond more often to an $\mathrm{S}-$ than to an $\mathrm{S}+$ under certain training conditions. This effect, shown by Group PA-Partial in Experiment 1, cannot be explained simply by appeal to the direct values of the stimuli involved in the ambiguous-cue task.

These results also dovetail with similar findings recently reported by Urcuioli (2006). In that study, pigeons were trained on a Simon task (Urcuioli et al., 2005) in which the particular color presented on one of two keys signaled whether pecking directly to that key or to the opposite key (i.e., away from the color cue) would be reinforced. Accuracy on the former, corresponding trials was noticeably lower than on the latter, noncorresponding trials. Furthermore, corresponding-trial accuracies fell below chance when correct responses on these trials (i.e., pecking directly to the color cue) were intermittently reinforced. Urcuioli (2006) showed that the pigeon Simon task could

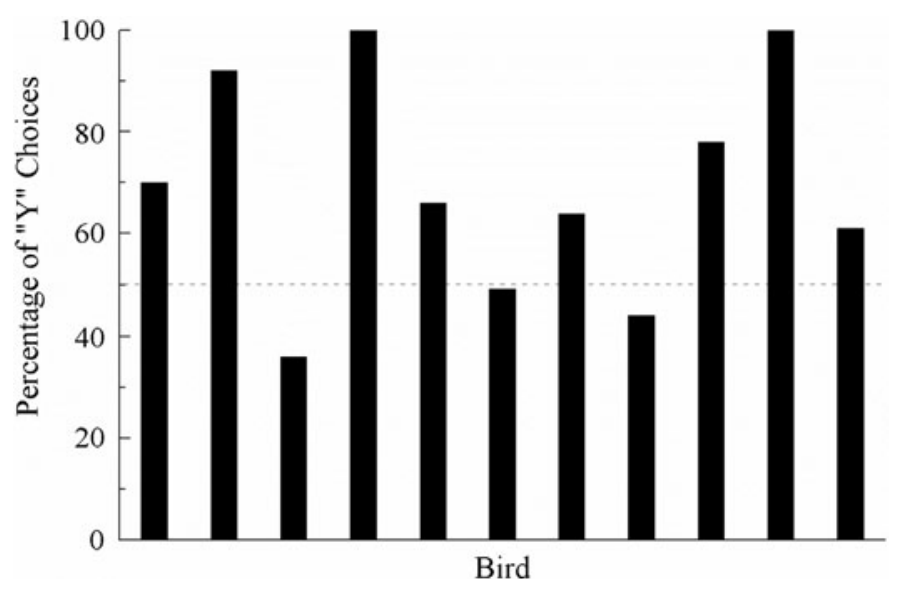

Figure 2. The percent choice of the $S-$ stimulus from the XY training trials $(Y)$ for individual birds in Experiment 2 averaged over the 10 probe-test sessions. 
be conceptualized as two concurrent ambiguous-cue tasks in which the functional $\mathrm{S}+$ and $\mathrm{S}-$ stimuli were compounds consisting of each color and the left versus right key location on which it appeared. The same assumptions about value transfer made sense of the peculiar finding that pigeons chose the $\mathrm{S}-$ on the corresponding trials more often than a partially reinforced $\mathrm{S}+$ that appeared with it.

In addition, Urcuioli (2006, Experiment 6) showed that lowering the probability of reinforcement on the noncorresponding trials of the pigeon Simon task-even to zero-enhanced the accuracy on the corresponding trials. The former are like NA trials of an ambiguous-cue discrimination, and the latter are like the PA trials. This intermittent reinforcement manipulation, then, produced the same effect seen in Groups NA-Partial in Experiment 1 of the present study. Although no appeal to value transfer is necessary to explain the increase in PA-trial (or corresponding-trial) accuracies with partial reinforcement of correct NA-trial (or noncorrespondingtrial) choices, it seems reasonable to suppose that such a process operates under these conditions as well, given the effects of intermittent reinforcement of PA-trial (or corresponding-trial) performances and the preference results of Experiment 2.

It may be of interest to note that transitive-inferencelike tasks studied with nonhuman animals (e.g., von Fersen et al., 1991) are essentially a set of ambiguouscue discriminations when all trial types $(\mathrm{A}+\mathrm{B}-, \mathrm{B}+\mathrm{C}-$, $\mathrm{C}+\mathrm{D}-$, and $\mathrm{D}+\mathrm{E}-$ ) are intermixed within each session. This might account for the reported difficulty subjects have in learning the task with intermixed trials (e.g., Steirn et al., 1995). Furthermore, the particularly low levels of accuracy observed on the $\mathrm{C}-\mathrm{D}$ trials may result from the same processes that affected performance in Group PA-Partial in Experiment 1. The C-D trials seem very much like partially reinforced $\mathrm{PA}$ trials (give that $\mathrm{C}$ is nonreinforced in the $\mathrm{B}-\mathrm{C}$ pair) that occur in the context of D-E, which resembles an NA trial.

Leary $(1956,1958)$ appeared to have anticipated value transfer in his early studies of ambiguous-cue performance by monkeys. He found that choice of the rewarded object on the first trial of a discrimination task induced a preference for the $\mathrm{S}$ - object relative to a novel object, and that this was not simply a familiarity effect. Leary interpreted his results as evidence that an $\mathrm{S}$ - becomes attractive through generalization of the excitatory tendency of the $\mathrm{S}+$ with which it appears. If we broadly interpret such generalization to include the mechanisms proposed to underlie value transfer (Zentall, Sherburne, et al., 1996), Leary's data may very well have arisen from the same processes contributing to the present results.

\section{AUTHOR NOTE}

Some of these results were presented at the Conference on Comparative Cognition, Melbourne, FL, in March 2006. The authors thank Kate
Willaman and Marco Vasconcelos for their assistance in running subjects. Correspondence concerning this article should be addressed to P. J. Urcuioli, Department of Psychological Sciences, Purdue University, 703 Third Street, West Lafayette, IN 47907-2004 (e-mail: uche@psych.purdue.edu).

\section{REFERENCES}

Aitken, M. R. F. (1999). Alternative accounts are preferable to value transfer theory: Commentary on Dorrance, Kaiser, and Zentall (1998). Animal Learning \& Behavior, 27, 490-493.

BERCH, D. B. (1974). A theoretical analysis of the PAN ambiguous-cue problem. Learning \& Motivation, 5, 135-148.

Boyer, W. N., \& Polidora, V. J. (1972). An analysis of the solution of PAN ambiguous-cue problems by rhesus monkeys. Learning \& Motivation, 3, 325-333.

Fletcher, H. J., \& GARSKe, J. P. (1972). Response competition in monkeys' solution of PAN ambiguous-cue problems. Learning \& Motivation, 3, 334-340.

Fletcher, H. J., Grogg, T. M., \& Garske, J. P. (1968). Ambiguous-cue problem performance of children, retardates, and monkeys. Journal of Comparative \& Physiological Psychology, 66, 477-482.

HALL, G. (1980). An investigation of ambiguous-cue learning in pigeons. Animal Learning \& Behavior, 8, 282-286.

LEARY, R. W. (1956). The rewarded, the unrewarded, the chosen, and the unchosen. Psychological Reports, 2, 91-97.

LEARY, R. W. (1958). The learning of ambiguous-cue problems by monkeys. American Journal of Psychology, 71, 718-724.

RicharDS, R. W., \& MARCATTILIO, A. J. (1975). Intermittency of reinforcement during NA trials and performance on the ambiguous-cue problem. Canadian Journal of Psychology, 29, 210-223.

RoDGER, R. S. (1975). The number of non-zero, post hoc contrasts from ANOVA and error rate: I. British Journal of Mathematical \& Statistical Psychology, 28, 71-78.

Steirn, J. N., Weaver, J. E., \& Zentall, T. R. (1995). Transitive inference in pigeons: Simplified procedures and a test of value transfer. Animal Learning \& Behavior, 23, 76-82.

THOMPSON, R. (1954). Approach versus avoidance in an ambiguous-cue discrimination problem in chimpanzees. Journal of Comparative \& Physiological Psychology, 47, 133-135.

URCUIOLI, P. J. (2006). When discrimination fails (or least falters). Journal of Experimental Psychology: Animal Behavior Processes, 32,359-370.

URCUIOLI, P. J., Vu, K.-P. L., \& Proctor, R. W. (2005). A Simon effect in pigeons. Journal of Experimental Psychology: General, 134, 93-107.

von Fersen, L., Wynne, C. D. L., Delius, J. D., \& Staddon, J. E. R. (1991). Transitive inference formation in pigeons. Journal of Experimental Psychology: Animal Behavior Processes, 17, 334-341.

ZEAMAN, D., \& HouSE, B. J. (1962). Approach and avoidance in the discrimination learning of retardates. Child Development, 33, 355-172.

Zentall, T. R., \& Clement, T. S. (2001). Simultaneous discrimination learning: Stimulus interactions. Animal Learning \& Behavior, 29, 311-325.

Zentall, T. R., \& Sherburne, L. M. (1994). Transfer of value from $\mathrm{S}+$ to $\mathrm{S}-$ in a simultaneous discrimination. Journal of Experimental Psychology: Animal Behavior Processes, 20, 176-183.

Zentall, T. R., Sherburne, L. M., Roper, K. L., \& Kraemer, P. J. (1996). Value transfer in a simultaneous discrimination appears to result from within-event Pavlovian conditioning. Journal of Experimental Psychology: Animal Behavior Processes, $2 \overline{2,68-75 .}$ 